\title{
Effects of tiotropium + olodaterol versus tiotropium or placebo by COPD disease severity and previous treatment history in the OTEMTO ${ }^{\circledR}$ studies
}

Dave Singh ${ }^{1 *}$, Mina Gaga ${ }^{2}$, Olaf Schmidt ${ }^{3}$, Leif Bjermer ${ }^{4}$, Lars Grönke ${ }^{5}$, Florian Voß ${ }^{5}$ and Gary T. Ferguson ${ }^{6}$

\begin{abstract}
Background: As lung function declines rapidly in the early stages of chronic obstructive pulmonary disease (COPD), the effects of bronchodilators in patients with moderate disease and those who have not previously received maintenance therapy are of interest. OTEMTO 1 and 2 were two replicate, 12-week, Phase III studies investigating the benefit of tiotropium + olodaterol on lung function and quality of life in patients with moderate to severe disease. Post hoc analyses were performed to assess the benefits for patients according to disease severity and treatment history.
\end{abstract}

Methods: Four subgroup analyses were performed: Global initiative for chronic Obstructive Lung Disease (GOLD) 2/3, GOLD A/B/C/D, treatment naive/not treatment naive and receiving inhaled corticosteroids (ICS) at baseline/not receiving ICS at baseline. Primary end points were change in forced expiratory volume in $1 \mathrm{~s}\left(\mathrm{FEVV}_{1}\right)$ area under the curve from 0 to $3 \mathrm{~h}$ response, change in trough FEV ${ }_{1}$ and St George's Respiratory Questionnaire (SGRQ) total score. Transition Dyspnoea Index (TDI) focal score was a secondary end point, and SGRQ and TDI responder analyses were further end points; all were assessed at 12 weeks.

Results: In all subgroups, patients receiving tiotropium + olodaterol responded better overall than those receiving tiotropium monotherapy. Improvements with tiotropium + olodaterol over placebo or tiotropium monotherapy were noted across GOLD 2/3 and GOLD A/B/C/D; however, improvements in SGRQ total score were most evident in the GOLD B subgroup. Moreover, lung-function outcomes were generally greater in those patients who had been receiving previous long-acting bronchodilator and/or ICS maintenance treatment.

Conclusions: These data suggest that tiotropium + olodaterol should be considered as a treatment option in patients with moderate COPD who are initiating maintenance therapy, as well as those with more severe disease.

Trial registration: ClinicalTrials.gov: NCT01964352 and NCT02006732.

Keywords: COPD, Long-acting bronchodilator, Tiotropium, Olodaterol, Severity, Treatment history

\footnotetext{
* Correspondence: dsingh@meu.org.uk

${ }^{1}$ Centre for Respiratory Medicine and Allergy, The Medicines Evaluation Unit,

University Hospital of South Manchester Foundation Trust, University of

Manchester, Manchester, Southmoor Road, Manchester M23 9QZ, UK

Full list of author information is available at the end of the article
} 


\section{Background}

The use of long-acting $\beta_{2}$-agonists (LABAs) and longacting muscarinic antagonists (LAMAs) is central to the pharmacological management of patients with chronic obstructive pulmonary disease (COPD) [1, 2]. The aim of treatment is to improve lung function, reduce symptoms and risk of exacerbations, and improve health status [1].

Tiotropium is an established once-daily LAMA that improves lung function, patient-reported outcomes such as dyspnoea and quality of life, and reduces exacerbations in patients with COPD [3-9]. Olodaterol is a novel LABA that provides 24-h bronchodilation and symptomatic benefits in patients with COPD [10-13]. The combination of tiotropium + olodaterol has been extensively studied in a large Phase III clinical trial programme that demonstrated improvements in lung function and patient-reported outcomes compared to tiotropium monotherapy, with tolerability similar to tiotropium [14-18]. A recent post hoc analysis of the TONADO ${ }^{\circ}$ studies showed that tiotropium + olodaterol significantly improved lung function in Global initiative for chronic Obstructive Lung Disease (GOLD) severity groups 2, 3 and 4, compared to monotherapy, irrespective of whether patients had received prior LAMA or LABA maintenance treatment [19].

The OTEMTO ${ }^{\circ}$ studies were two replicate, randomised, double-blind, Phase III studies investigating the effects of tiotropium + olodaterol on lung function and quality of life [16]. Unlike the TONADO ${ }^{\circ}$ trials, OTEMTO ${ }^{\circ}$ included a placebo arm as well as tiotropium as an active comparator in order to properly understand the effect size of tiotropium + olodaterol on patient-reported outcomes. Overall, tiotropium + olodaterol was superior to tiotropium at improving quality of life as measured by the St George's Respiratory Questionnaire (SGRQ) and, importantly, the improvement versus placebo was $>4$ units (the minimum clinically important difference) [16].

The OTEMTO ${ }^{\circ}$ studies provided the opportunity to study the effectiveness of tiotropium + olodaterol in different COPD subgroups based on lung function (GOLD 2 or 3), GOLD combined assessment (A, B, C or D) and previous treatment focusing on treatment-naive patients (no prior use of LAMAs, LABAs and/or inhaled corticosteroids [ICS]). We, therefore, performed post hoc analyses to evaluate the efficacy of tiotropium + olodaterol compared to placebo and tiotropium monotherapy in subgroups of patients defined by GOLD category (GOLD 2-3 and GOLD A-D) and by previous treatment history (treatment naive and baseline ICS use) after 12 weeks of treatment. The aim of this analysis was to understand if the benefits of tiotropium + olodaterol vary according to GOLD categorisation or previous treatment.

\section{Methods}

Study design

As presented elsewhere [16], OTEMTO ${ }^{\circ} 1$ (1237.25; NCT01964352) and 2 (1237.26; NCT02006732) were two replicate, double-blind, placebo-controlled studies. Patients were randomised to one of four treatment arms to receive once-daily tiotropium + olodaterol $2.5 / 5 \mu \mathrm{g}$, tiotropium + olodaterol $5 / 5 \mu \mathrm{g}$, tiotropium $5 \mu \mathrm{g}$ or placebo, all delivered via the Respimat $^{\circ}$ inhaler.

\section{Patients}

Patients were included if they were aged $\geq 40$ years with moderate or severe COPD (GOLD 2-3; postbronchodilator forced expiratory volume in $1 \mathrm{~s}$ [FEV $\left.\mathrm{FE}_{1}\right]$ $<80 \%$ and $\geq 30 \%$ of predicted normal), $\mathrm{FEV}_{1} /$ forced vital capacity $<70 \%$ predicted and a smoking history of $>10$ pack-years. Exclusion criteria included significant disease other than COPD, a history of asthma, COPD exacerbation or symptoms of lower respiratory tract infection within the previous 3 months.

Patients continued their ICS therapy if they were on a stable dose for 6 weeks prior to screening but were not permitted to take LAMAs or LABAs other than study medication. Short-acting muscarinic antagonists were permitted only during the screening period and openlabel salbutamol was provided as rescue medication for use throughout the study.

The studies were conducted in accordance with the Declaration of Helsinki, International Conference on Harmonisation Harmonised Tripartite Guideline for Good Clinical Practice and local regulations. Signed, informed consent was obtained from all patients. The studies were approved by the relevant Institutional Review Board/Independent Ethics Committees and competent authorities; full details are included in Additional file 1.

\section{Outcomes}

There were three primary end points in the OTEMTO ${ }^{\circ}$ studies, all at 12 weeks: SGRQ total score, change from baseline in trough $\mathrm{FEV}_{1}$ and change from baseline in $\mathrm{FEV}_{1}$ area under the curve from 0 to $3 \mathrm{~h}\left(\mathrm{AUC}_{0-3}\right)$. Mahler Transition Dyspnoea Index (TDI) focal score was a secondary end point; responder analyses for SGRQ and TDI focal scores were further end points.

\section{Assessments}

As described in the primary manuscript [16], pulmonary function tests were performed at $1 \mathrm{~h}$ pre-dose, $10 \mathrm{~min}$ predose, 5,15 and 30 min post-dose and 1,2 and $3 \mathrm{~h}$ postdose at baseline and week 12, and at $10 \mathrm{~min}$ pre-dose only after 2 and 6 weeks of treatment. The final trough $\mathrm{FEV}_{1}$ measurement was taken the day after the week 12 visit (at $23 \mathrm{~h}$ and $23 \mathrm{~h} 50$ min post-dose). SGRQ was completed in the clinic at baseline and weeks 6 and 12. At weeks 6 and 
12, trained clinic staff conducted the TDI interview, which asks patients about breathlessness compared to baseline.

\section{Subgroup analysis}

For all of the post hoc analyses presented here, data from $\mathrm{OTEMTO}^{\circ} 1$ and 2 were combined to increase the robustness of the analyses. As tiotropium + olodaterol $5 / 5 \mu \mathrm{g}$ is the licensed dose, we are only presenting the results of these subgroup analyses for the tiotropium + olodaterol $5 / 5 \mu \mathrm{g}$, tiotropium $5 \mu \mathrm{g}$ and placebo groups.

Four subgroup analyses were performed: GOLD 2 or 3, GOLD A-D (based on the modified Medical Research Council dyspnoea scale), maintenance treatment naive (no prior use of LAMAs, LABAs and/or ICS) and baseline use of ICS. Results are presented for the three primary end points $\left(\mathrm{FEV}_{1} \mathrm{AUC}_{0-3}\right.$ response, trough $\mathrm{FEV}_{1}$ response and SGRQ total score), the SGRQ responder analysis, TDI focal score and TDI focal score responder analysis.

For the SGRQ responder analysis, patients were classed as responders if their SGRQ total score improved from baseline to week 12 by $\geq 4$ units. Odds ratios were calculated between groups using a logistical regression including the fixed categorical effect of treatment. A restricted maximum likelihood-based mixed effects model repeated measures approach was used for the analysis of continuous end points, including the fixed categorical effects of treatment, test day and treatment-by-test-day interaction, as well as the continuous fixed covariates of baseline and baseline-by-test-day interaction.

The TDI responder analysis was based on the TDI focal score; patients were classed as responders if they had a value that was $\geq 1.0$ unit.

As these analyses are post hoc and performed within subgroups with potentially small sample sizes, they are not powered for statistical comparisons within subgroups; therefore, results are presented as forest plots of treatment differences with corresponding $95 \%$ confidence intervals (CIs). Differences in treatment effects between subgroups are discussed and emphasis is not put on statistical significance within subgroups alone (assessed based on the $95 \% \mathrm{CI}$ ). No adjustment for multiple comparisons has been performed.

\section{Results}

Patient disposition and baseline characteristics

In $\mathrm{OTEMTO}^{\circ} 1$ and 2 , a total of 1623 patients were randomised, with 1621 receiving treatment and 1525 completing the study (Fig. 1). Patient demographics and

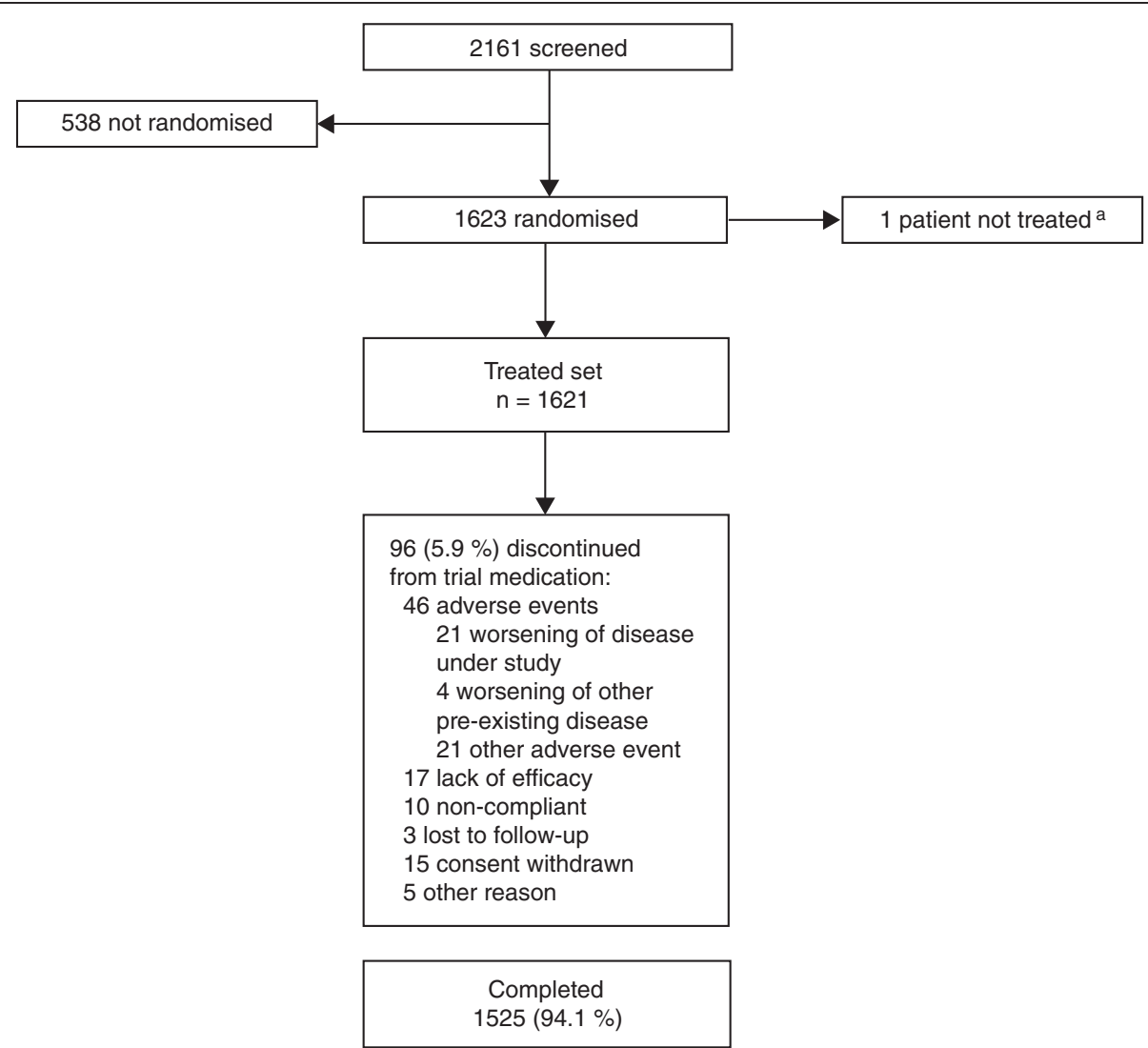

Fig. 1 Patient disposition in OTEMTO ${ }^{\circledR} 1$ and 2 (combined data). ${ }^{a} 1623$ patients were randomised; 1 patient was entered twice but counted only once in the treated set 
baseline characteristics by subgroup and overall population are shown in Table 1. Overall baseline characteristics such as age and sex were similar across subgroups. As expected, mean $\mathrm{FEV}_{1}$ values and baseline pulmonary medications also differed between subgroups. Patients who were already receiving maintenance therapy tended to be ex-smokers and to have worse lung function compared to those who were treatment naive.

\section{Efficacy}

\section{GOLD 2 and 3 subgroups}

Trough $\mathrm{FEV}_{1}$ responses and SGRQ total scores improved with tiotropium + olodaterol in both GOLD 2 and 3 subgroups after 12 weeks of treatment compared to baseline (Figs. 2 and 3). In the GOLD 2 subgroup, the adjusted mean (standard error) SGRQ total score change from baseline at week 12 was $-4.7(0.6)$ in the tiotropium + olodaterol $5 / 5 \mu \mathrm{g}$ arm, $-2.2(0.6)$ in the tiotropium $5 \mu \mathrm{g}$ arm and $-0.7(0.6)$ in the placebo arm. In the GOLD 3 subgroup, the adjusted mean (standard error) SGRQ total score change from baseline at week 12 was $-5.6(0.8)$ in the tiotropium + olodaterol $5 / 5 \mu \mathrm{g}$ arm, $-4.2(0.9)$ in the tiotropium $5 \mu \mathrm{g}$ arm and $0.5(0.9)$ in the placebo arm. Similar improvements were also seen in the absolute SGRQ score (Additional file 1: Table S1). Improvements after 12 weeks compared to baseline were also observed for tiotropium + olodaterol $5 / 5 \mu \mathrm{g}$ in the GOLD 2 and 3 subgroups for $\mathrm{FEV}_{1} \mathrm{AUC}_{0-3}$ response (292-326 mL) and TDI (1.67-1.85) (Additional file 1: Table S1).

Treatment differences are shown in Fig. 4 for $\mathrm{FEV}_{1}$ $\mathrm{AUC}_{0-3}$, trough $\mathrm{FEV}_{1}$ responses, SGRQ total score and TDI focal score. In general, results in GOLD 2 patients were similar to GOLD 3, with larger CIs for GOLD 3 due to the smaller number of patients in this group. The comparison of tiotropium + olodaterol versus placebo showed significant treatment effects for all end points in GOLD 2 and 3 patients ( $95 \% \mathrm{CI}$ did not cross zero). The comparisons of tiotropium + olodaterol versus tiotropium showed significant differences between treatment for most end points, except for trough $\mathrm{FEV}_{1}$, in both GOLD 2 and 3, and, as discussed, SGRQ in GOLD 3 patients, which is most likely due to the reduced sample size as treatment differences are similar between the groups.

\section{GOLD A-D subgroups}

Tiotropium + olodaterol was more effective at improving $\mathrm{FEV}_{1} \mathrm{AUC}_{0-3}$ than tiotropium monotherapy and placebo in GOLD A-D subgroups (Fig. 5). Trough $\mathrm{FEV}_{1}$ responses improved significantly with tiotropium + olodaterol compared to placebo in GOLD A-D subgroups. Improvements with tiotropium + olodaterol were numerically better compared to tiotropium monotherapy in GOLD A, B and D groups, although these improvements were not significant, as the $95 \% \mathrm{CI}$ crossed zero. In general, lung-function treatment comparisons were similar across GOLD A-D subgroups.

SGRQ total score and TDI focal score improved significantly, to a greater extent with tiotropium + olodaterol compared to placebo in GOLD A-D groups (Fig. 5b and c). Treatment effects were similar between subgroups with overlapping $95 \%$ CIs. When comparing tiotropium + olodaterol to tiotropium alone, treatment effects differed between subgroups and improvements in SGRQ total score were most evident in the GOLD B subgroup.

\section{Treatment-naive patients}

Tiotropium + olodaterol was more effective than tiotropium monotherapy and placebo for $\mathrm{FEV}_{1} \mathrm{AUC}_{0-3}$ and trough $\mathrm{FEV}_{1}$, both in patients with and without previous maintenance therapy, although for trough $\mathrm{FEV}_{1}$ the $95 \%$ CI crossed zero for the comparison with tiotropium in treatment-naive individuals. The effect sizes were generally greater in those patients who had been receiving previous maintenance therapy (Fig. 6a). The mean improvements in SGRQ total score and TDI focal score were similar for patients with and without previous maintenance therapy and significant for both treatment comparisons (Fig. 6b and c).

\section{ICS use at baseline}

Tiotropium + olodaterol was more effective at improving lung-function outcomes than tiotropium monotherapy and placebo, both in patients who were receiving ICS treatment at baseline and those who were not. $\mathrm{FEV}_{1}$ $\mathrm{AUC}_{0-3}$ and trough $\mathrm{FEV}_{1}$ responses improved in both groups (Fig. 7a), with some evidence for a superior response for patients receiving ICS at baseline. Baseline SGRQ scores were higher for patients receiving ICS treatment at baseline, compared to those not receiving baseline ICS (44.4 and 41.5, respectively). In contrast to lung-function outcomes, the improvement in SGRQ total scores with tiotropium + olodaterol compared to tiotropium or placebo was greater in patients who were not receiving ICS at baseline (Fig. 7b and c).

\section{Responder analyses across subgroups}

Responder analyses for SGRQ total score demonstrated that a greater proportion of patients responded with tiotropium + olodaterol compared to tiotropium monotherapy or placebo for all subgroups (Additional file 1: Figure S1a) with significant improvements compared to placebo in all subgroups except GOLD A. Overall, treatment differences for tiotropium + olodaterol compared to tiotropium monotherapy or placebo were similar between subgroups, with widely overlapping $95 \%$ CIs. In the GOLD 2 subgroup, $52.8 \%$ of patients in the tiotropium + olodaterol $5 / 5 \mu \mathrm{g}$ arm and $39.2 \%$ in the 
Table 1 Patient demographics and baseline characteristics by subgroups and overall (combined OTEMTO 1 and 2; treated set)

\begin{tabular}{|c|c|c|c|c|c|c|c|c|c|c|c|}
\hline & GOLD 2 & GOLD 3 & GOLD A & GOLD B & GOLD C & GOLD D & Naive: no & Naive: yes & ICS: no & ICS: yes & Overall \\
\hline Patients, n & 1042 & 570 & 486 & 483 & 250 & 400 & 943 & 678 & 1013 & 608 & 1621 \\
\hline Male, n (\%) & $609(58.4)$ & $374(65.6)$ & $298(61.3)$ & $271(56.1)$ & $167(66.8)$ & $250(62.5)$ & $574(60.9)$ & $413(60.9)$ & $632(62.4)$ & $355(58.4)$ & $987(60.9)$ \\
\hline Mean (SD) age, years & $64.3(8.7)$ & $65.5(7.9)$ & $64.3(8.1)$ & $64.4(9.0)$ & $65.2(8.6)$ & $65.4(7.9)$ & $65.6(8.2)$ & $63.5(8.6)$ & $63.9(8.4)$ & $66.1(8.3)$ & $64.7(8.4)$ \\
\hline \multicolumn{12}{|l|}{ Smoking status, n (\%) } \\
\hline Ex-smoker & $554(53.2)$ & $300(52.6)$ & $260(53.5)$ & $255(52.8)$ & $135(54.0)$ & $207(51.8)$ & $560(59.4)$ & $298(44.0)$ & $473(46.7)$ & $385(63.3)$ & $858(52.9)$ \\
\hline Current smoker & $488(46.8)$ & $270(47.4)$ & $226(46.5)$ & $228(47.2)$ & $115(46.0)$ & $193(48.3)$ & $383(40.6)$ & $380(56.0)$ & $540(53.3)$ & $223(36.7)$ & $763(47.1)$ \\
\hline \multicolumn{12}{|c|}{ Mean (SD) pre-bronchodilator } \\
\hline $\mathrm{FEV}_{1}, \mathrm{~L}$ & $1.557(0.460)$ & $0.969(0.262)$ & $1.617(0.469)$ & $1.499(0.445)$ & $1.094(0.353)$ & $0.988(0.327)$ & $1.283(0.459)$ & $1.436(0.521)$ & $1.422(0.512)$ & $1.221(0.428)$ & $1.347(0.492)$ \\
\hline \multicolumn{12}{|c|}{ Mean (SD) post-bronchodilator } \\
\hline $\mathrm{FEV}_{1}, \mathrm{~L}$ & $1.754(0.468)$ & $1.146(0.274)$ & $1.820(0.472)$ & $1.690(0.455)$ & $1.269(0.370)$ & $1.167(0.336)$ & $1.476(0.475)$ & $1.619(0.532)$ & $1.614(0.522)$ & $1.406(0.444)$ & $1.536(0.504)$ \\
\hline $\mathrm{FEV}_{1} \%$ predicted & $62.94(7.98)$ & $41.09(5.54)$ & $63.66(8.08)$ & $62.09(7.72)$ & $44.86(9.80)$ & $42.58(9.06)$ & $53.91(12.86)$ & $56.75(12.57)$ & $56.65(12.55)$ & $52.52(12.83)$ & $55.10(12.81)$ \\
\hline $\mathrm{FEV}_{1} / \mathrm{FVC}$ ratio, \% (SD) & $54.54(8.21)$ & $42.82(9.62)$ & $54.66(8.33)$ & $54.54(8.14)$ & $44.13(9.83)$ & $43.79(10.24)$ & $48.49(10.42)$ & $52.87(9.89)$ & $51.87(9.96)$ & $47.74(10.67)$ & $50.32(10.42)$ \\
\hline \multicolumn{12}{|c|}{ Baseline pulmonary medication, n (\%) } \\
\hline Any & $761(73.0)$ & $473(83.0)$ & $349(71.8)$ & $356(73.7)$ & $213(85.2)$ & $321(80.3)$ & $943(100)$ & 297 (43.8) & $632(62.4)$ & $608(100)$ & 1240 (76.5) \\
\hline ICS & $337(32.3)$ & 269 (47.2) & $131(27.0)$ & 173 (35.8) & $125(50.0)$ & $179(44.8)$ & 608 (64.5) & $0(0.0)$ & $0(0.0)$ & $608(100)$ & 608 (37.5) \\
\hline LAMA & 334 (32.1) & 221 (38.8) & $157(32.3)$ & $150(31.1)$ & $105(42.0)$ & $148(37.0)$ & $560(59.4)$ & $0(0.0)$ & $277(27.3)$ & $283(46.5)$ & $560(34.5)$ \\
\hline SAMA & $68(6.5)$ & $56(9.8)$ & $24(4.9)$ & $38(7.9)$ & $21(8.4)$ & $41(10.3)$ & $88(9.3)$ & $36(5.3)$ & $55(5.4)$ & 69 (11.3) & $124(7.6)$ \\
\hline LABA & 365 (35.0) & $261(45.8)$ & 149 (30.7) & $184(38.1)$ & $117(46.8)$ & $179(44.8)$ & $629(66.7)$ & $0(0.0)$ & $144(14.2)$ & 485 (79.8) & $629(38.8)$ \\
\hline SABA & $470(45.1)$ & $343(60.2)$ & $211(43.4)$ & $223(46.2)$ & 159 (63.6) & $224(56.0)$ & $542(57.5)$ & $276(40.7)$ & $447(44.1)$ & $371(61.0)$ & 818 (50.5) \\
\hline
\end{tabular}

GOLD A-D based on modified Medical Research Council dyspnoea scale. The inclusion criteria for this study only included patients with GOLD 2 or 3 disease; however, 8 patients were classed as GOLD 4 and 1 patient as GOLD 1 based on entrance spirometry results. As this is a small number, these patients were not included in the GOLD 2/3 subgroup analysis and are not included in the table

GOLD Global initiative for chronic Obstructive Lung Disease, ICS inhaled corticosteroids, SD standard deviation, FEV ${ }_{1}$ forced expiratory volume in $1 \mathrm{~s}$, FVC forced vital capacity, LAMA long-acting muscarinic antagonist,

SAMA short-acting muscarinic antagonist, $\angle A B A$ long-acting $\beta_{2}$-agonist, SABA short-acting $\beta$-agonist 


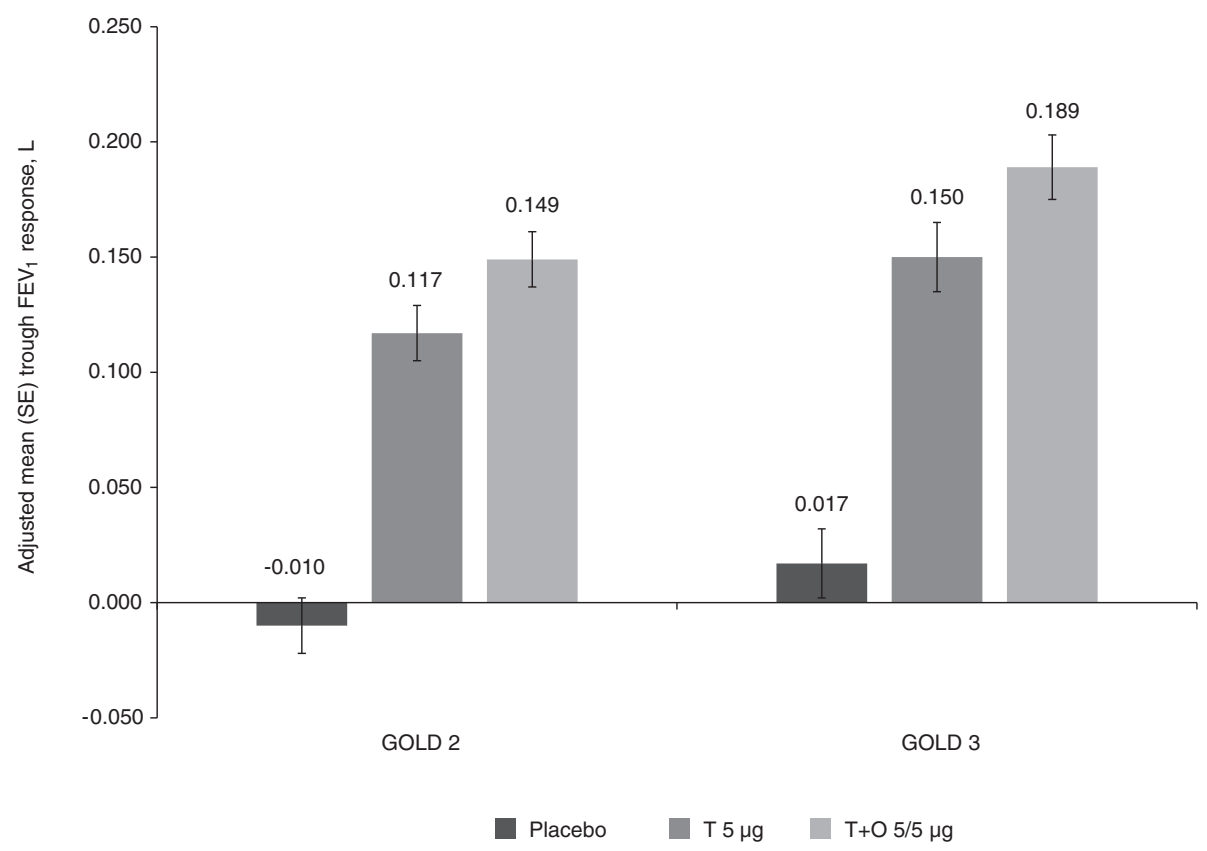

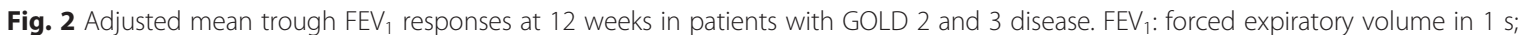
GOLD: Global initiative for chronic Obstructive Lung Disease; SE: standard error; T: tiotropium; O: olodaterol

tiotropium $5 \mu \mathrm{g}$ arm were SGRQ responders, compared to $33.7 \%$ in the placebo arm. In the GOLD 3 subgroup, $51.7 \%$ of patients in the tiotropium + olodaterol $5 / 5 \mu \mathrm{g}$ arm and $45.0 \%$ in the tiotropium $5 \mu \mathrm{g}$ arm were SGRQ responders, compared to $28.5 \%$ in the placebo arm. There was also an increased proportion of TDI responders with tiotropium + olodaterol compared to tiotropium monotherapy and placebo in all subgroups, with similar treatment effect overall (Additional file 1: Figure S1b). Improvements were significant compared to placebo in all subgroups and compared to tiotropium for most of the subgroups.

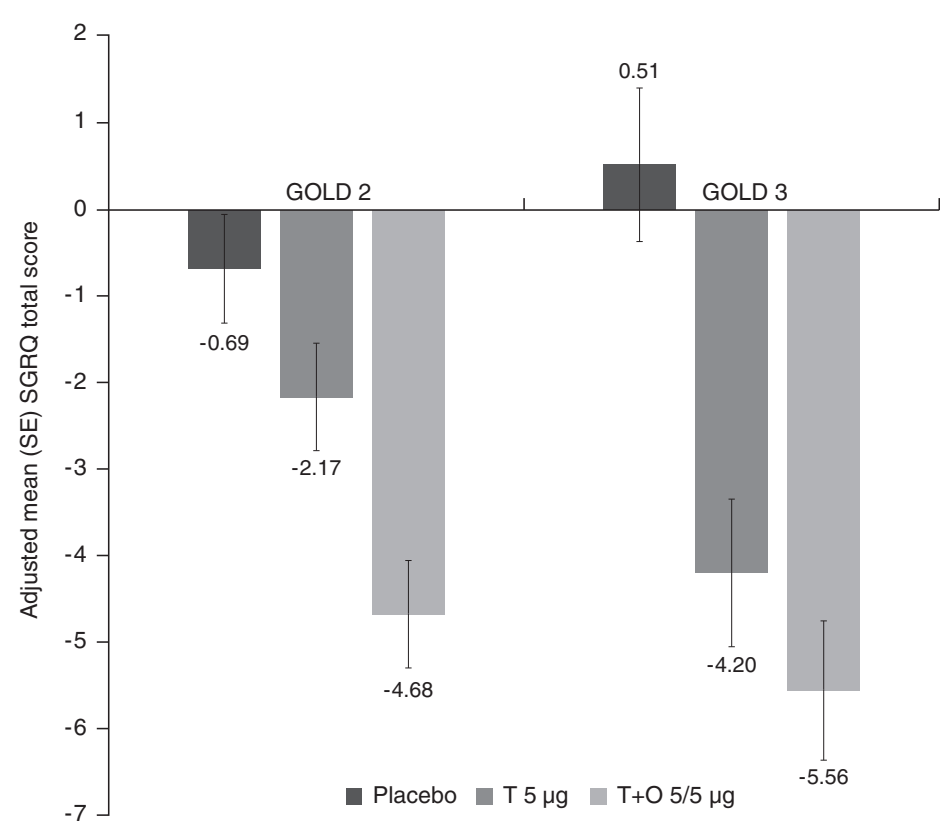

Fig. 3 Adjusted mean SGRQ total score at 12 weeks in patients with GOLD 2 and 3 disease. SGRQ: St George's Respiratory Questionnaire; GOLD: Global initiative for chronic Obstructive Lung Disease; SE: standard error; T: tiotropium; O: olodaterol 


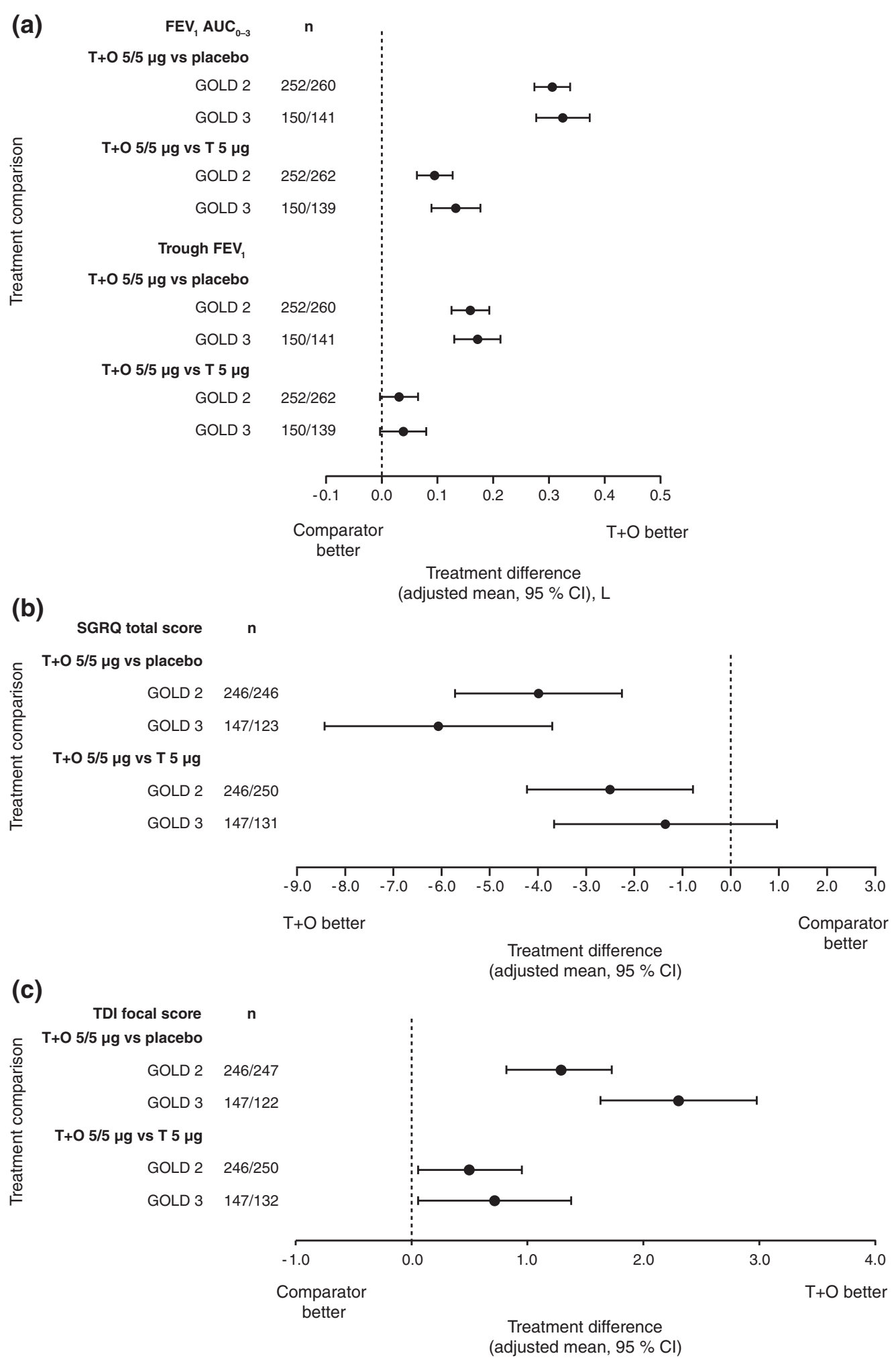

Fig. 4 (a) $\mathrm{FEV}_{1} \mathrm{AUC}_{0-3}$ and trough $\mathrm{FEV}_{1}$ responses, (b) SGRQ total score and (c) TDI focal score, all at 12 weeks: treatment comparisons for $\mathrm{T}+\mathrm{O}$ $5 / 5 \mu \mathrm{g}$ versus $\mathrm{T} 5 \mathrm{\mu g}$ and versus placebo in patients with GOLD 2 and 3 disease. FEV 1 : forced expiratory volume in $1 \mathrm{~s}$; $\mathrm{AUC}_{0-3}$ : area under the curve from 0-3 h; SGRQ: St George's Respiratory Questionnaire; TDI: Transition Dyspnoea Index; T: tiotropium; O: olodaterol; GOLD: Global initiative for chronic Obstructive Lung Disease; Cl: confidence interval 


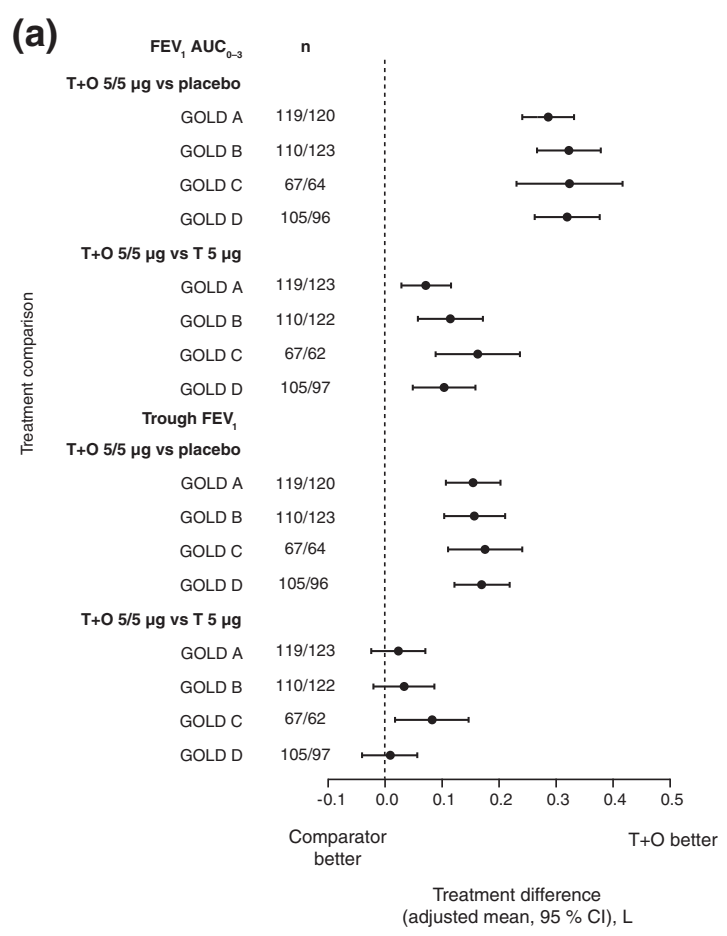

(b)

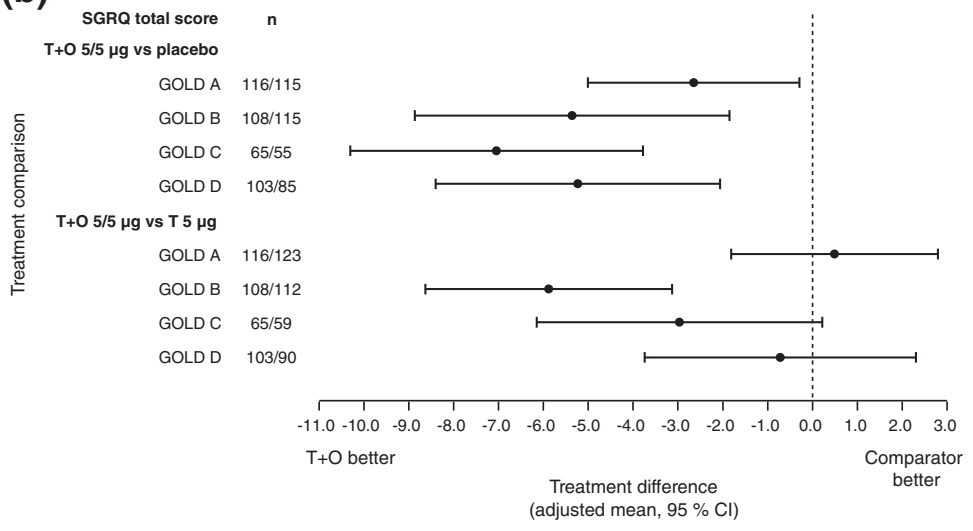

(c) TDI focal score $n$
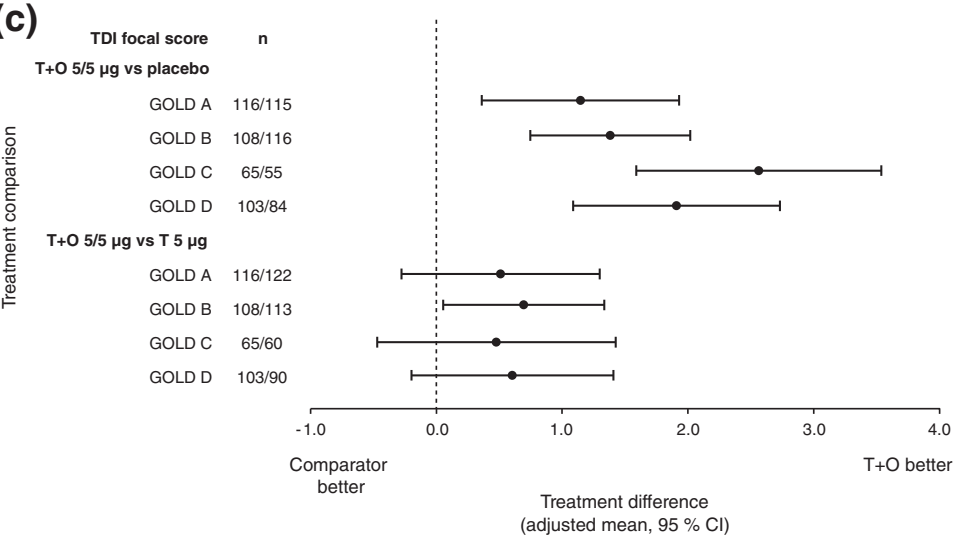

Fig. 5 (a) $\mathrm{FEV}_{1} \mathrm{AUC}_{0-3}$ and trough $\mathrm{FEV}_{1}$ responses, (b) SGRQ total score and (c) TDI focal score, all at 12 weeks: treatment comparisons for $\mathrm{T}+\mathrm{O}$ $5 / 5 \mu \mathrm{g}$ versus $T 5 \mu \mathrm{g}$ and versus placebo in patients with GOLD A-D disease. FEV ${ }_{1}$ : forced expiratory volume in $1 \mathrm{~s}$; $\mathrm{AUC}_{0-3}$ : area under the curve from 0-3 h; SGRQ: St George's Respiratory Questionnaire; TDI: Transition Dyspnoea Index; T: tiotropium; O: olodaterol; GOLD: Global initiative for chronic Obstructive Lung Disease; Cl: confidence interval 


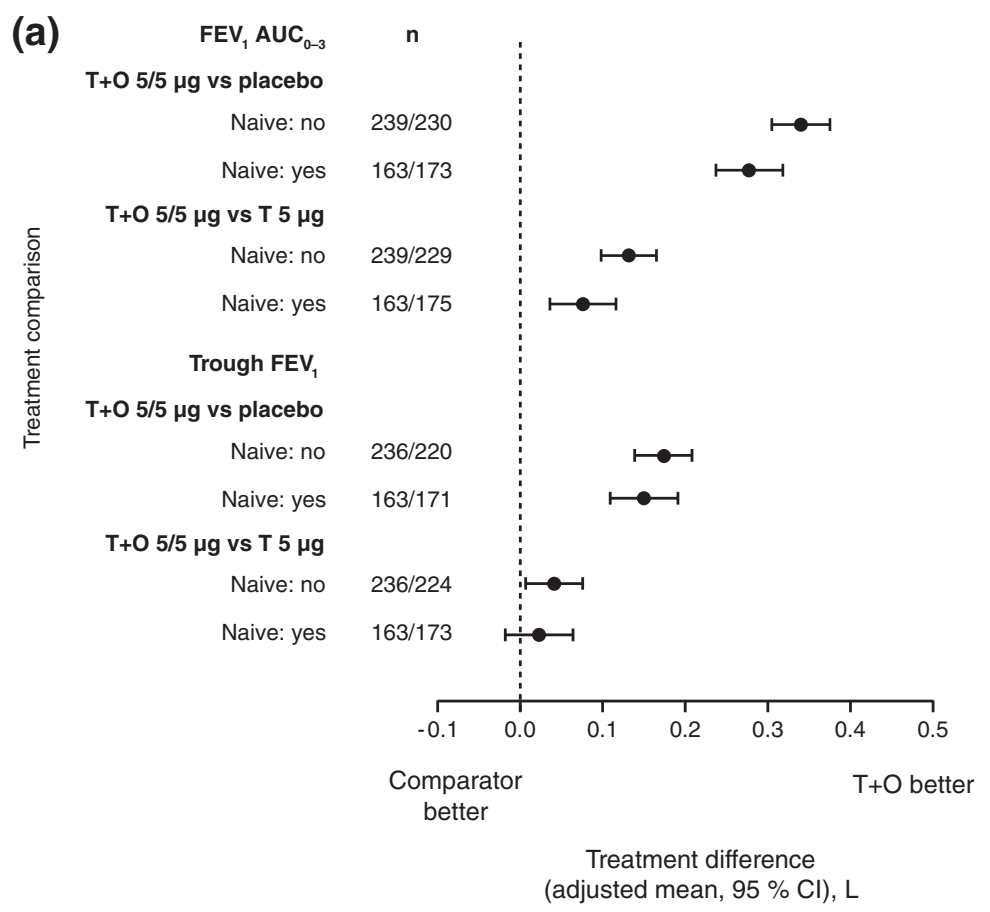

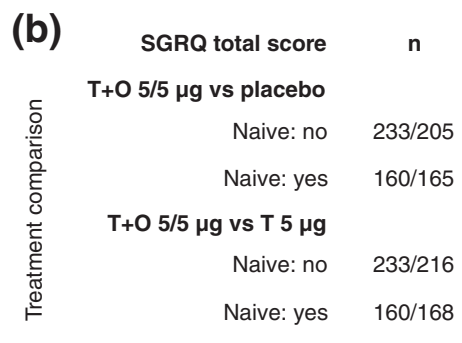
(adjusted mean, $95 \% \mathrm{Cl}$ ), L
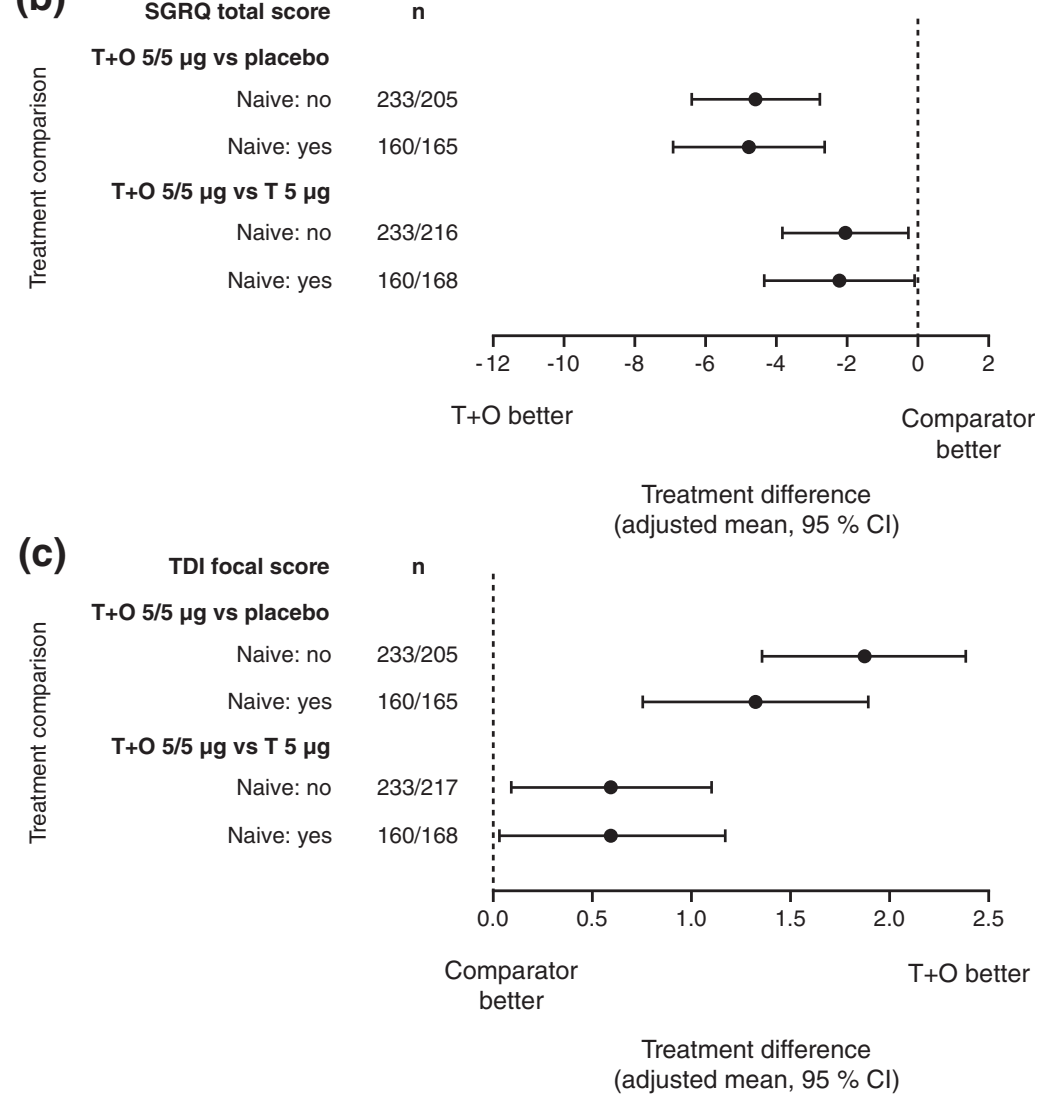

Fig. 6 (a) $\mathrm{FEV}_{1} \mathrm{AUC}_{0-3}$ and trough $\mathrm{FEV}_{1}$ responses, (b) SGRQ total score and (c) TDI focal score: treatment comparisons at 12 weeks for $\mathrm{T}+\mathrm{O}$ $5 / 5 \mu \mathrm{g}$ versus $\mathrm{T} 5 \mu \mathrm{g}$ and versus placebo in patients who were treatment naive/not treatment naive at baseline. FEV $\mathrm{V}_{1}$ : forced expiratory volume in 1 s; AUC $_{0-3}$ : area under the curve from 0-3 h; SGRQ: St George's Respiratory Questionnaire; TDI: Transition Dyspnoea Index; T: tiotropium; O: olodaterol; Cl: confidence interval 
(a)

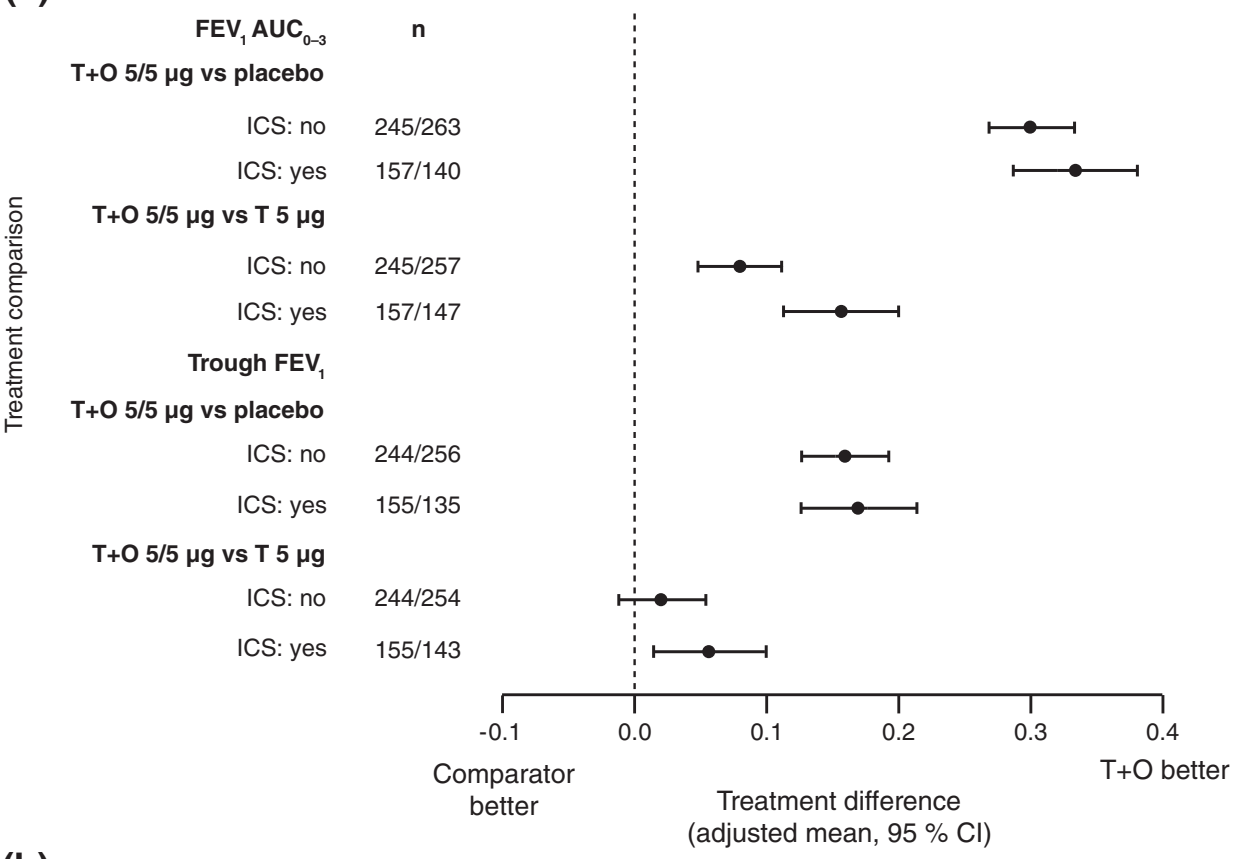

(b)
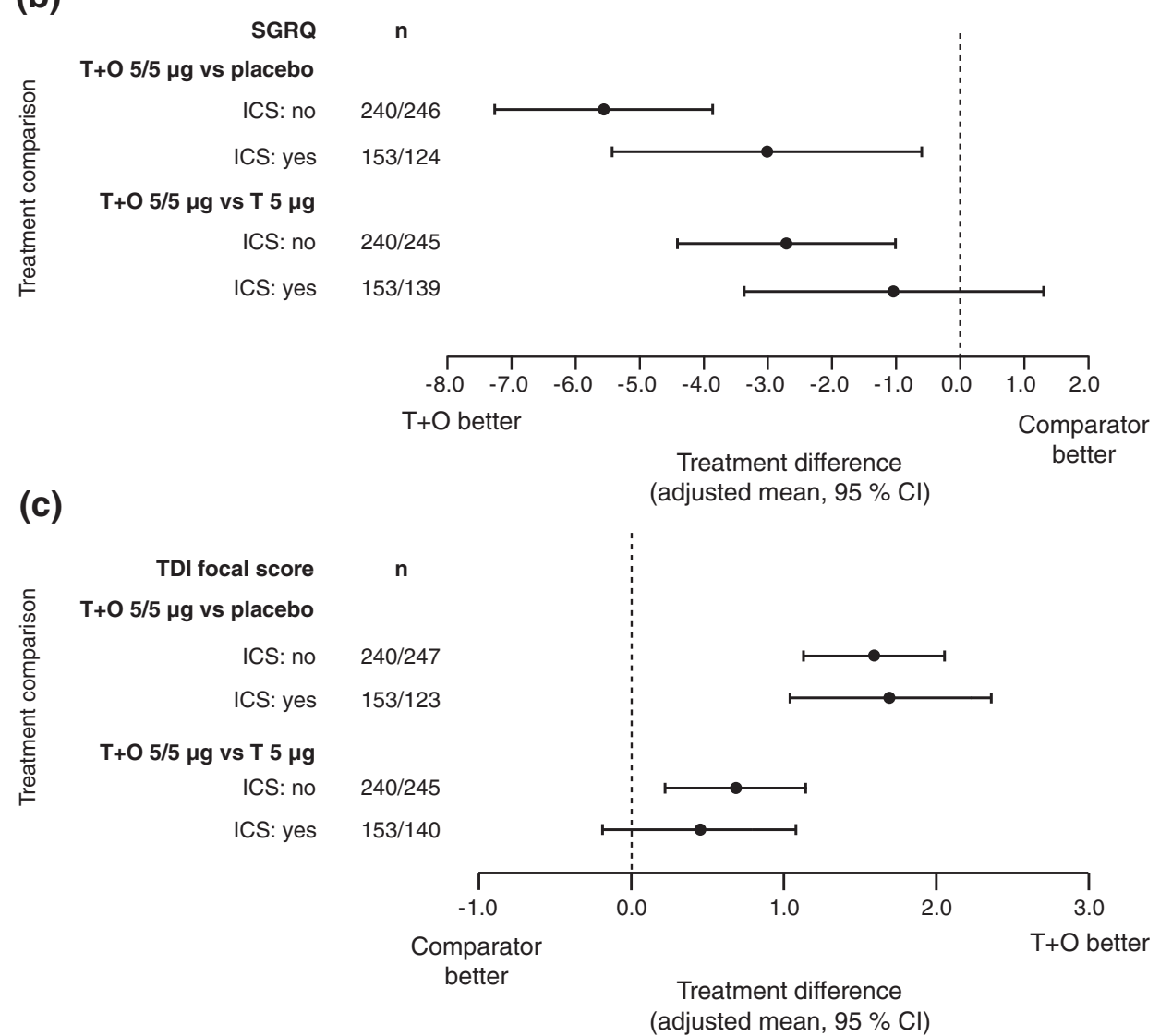

Fig. 7 (a) $\mathrm{FEV}_{1} \mathrm{AUC}_{0-3}$ and trough $\mathrm{FEV}_{1}$ responses, (b) SGRQ total score and (c) TDI focal score: treatment comparisons at 12 weeks for $\mathrm{T}+\mathrm{O}$ $5 / 5 \mu \mathrm{g}$ versus $\mathrm{T} 5 \mu \mathrm{g}$ and versus placebo in patients who were receiving/ not receiving ICS treatment at baseline. FEV $V_{1}$ : forced expiratory volume in $1 \mathrm{~s} ; \mathrm{AUC}_{0_{-3}}$ : area under the curve from 0-3 h; SGRQ: St George's Respiratory Questionnaire; TDI: Transition Dyspnoea Index; T: tiotropium; O: olodaterol; ICS: inhaled corticosteroids; Cl: confidence interval 


\section{Discussion}

The OTEMTO ${ }^{\circ}$ studies demonstrated that tiotropium + olodaterol improved lung function and quality of life in patients with moderate to severe COPD. Subgroup analyses confirm that tiotropium + olodaterol is equally effective in patients with moderate COPD (GOLD 2), as for those with severe disease (GOLD 3). Using the GOLD A-D categorisation, tiotropium + olodaterol showed a similar effect on lung function in all the subgroups but the benefit of this dual bronchodilator combination versus tiotropium monotherapy on patientreported outcomes was most apparent in GOLD B patients. Tiotropium + olodaterol was also superior to tiotropium monotherapy irrespective of previous treatment history, even in those patients naive to all maintenance therapy.

The responder analyses are an alternative way of understanding the treatment effects on patient-reported outcomes. Importantly, there was a greater proportion of SGRQ and TDI responders with tiotropium + olodaterol compared to tiotropium in GOLD 2 patients, demonstrating the potential benefits of tiotropium + olodaterol in terms of quality of life for patients with moderate disease.

Post hoc analyses of the TONADO $^{\circ}$ studies showed that tiotropium + olodaterol was superior to tiotropium and olodaterol monotherapies for lung-function changes in patient subgroups classified by lung-function impairment severity, age and previous treatment history [19]. Our analyses generally agree with these previous findings on lung function and further extend these observations by investigating responses in patients with GOLD A-D disease, as well as investigating patient-reported outcomes. The analysis of patients with GOLD A-D disease showed that the effects of tiotropium + olodaterol on lung function versus tiotropium monotherapy or placebo were similar in all subgroups. However, for SGRQ, the benefit of tiotropium + olodaterol was most apparent in GOLD B patients. There has been some debate about which patients with COPD benefit most from dual bronchodilator treatment compared to long-acting bronchodilator monotherapy. The current findings in GOLD B patients suggest that the symptomatic benefit of tiotropium + olodaterol is greater in patients with higher baseline symptoms and $\mathrm{FEV}_{1}>50 \%$ predicted and this may indicate that early combined treatment would be beneficial for these patients. The treatment difference was less pronounced in GOLD D patients compared to GOLD B patients, suggesting that in highly symptomatic patients with COPD (i.e. GOLD B and D) the greatest benefit of LAMA + LABA compared to long-acting bronchodilator monotherapy on patientreported outcomes is in patients with less severe airflow obstruction, although all groups showed benefit from
LAMA + LABA therapy. A note of caution for this interpretation of the GOLD A-D analysis is that the patients were split into four subgroups, thereby producing the smallest sample size of all the analyses presented here, and this reduced sample size may influence these results.

There was a trend towards greater lung-function improvements with tiotropium + olodaterol in patients who had received previous maintenance therapy. However, this pattern did not translate to a greater benefit on patient-reported outcomes. The mean treatment effects were similar in both groups of patients and the wide $95 \% \mathrm{CI}$ for the treatment effect in patients receiving previous maintenance treatment suggests a large variation between individuals in this group, and results may have been influenced by selection bias. Overall, we conclude that treatment with tiotropium + olodaterol showed evidence of similar efficacy, irrespective of previous maintenance treatment.

In this study, there was a large proportion of patients receiving ICS treatment at baseline, the majority of whom were classed as having severe or very severe (GOLD 3 or GOLD C/D) disease. This is in accordance with current GOLD guidelines, which recommend ICS treatment for patients with severe/very severe COPD and frequent exacerbations who are not adequately controlled with long-acting bronchodilators [1]. Clinical trials of LAMA + LABA combinations usually allow patients receiving ICS treatment to continue during the study. This is mostly for ethical reasons, as stepping patients down from both long-acting bronchodilator treatment and ICS in the placebo arm is potentially unsafe. However, the use of LAMA + LABA combination inhalers in real life is likely to be mostly without concomitant ICS treatment. Although this sub-analysis of $\mathrm{OTEMTO}^{\circ}$ cannot exclude an effect of ICS treatment on the clinical response to tiotropium + olodaterol, it would appear that any effect, if present, is small. Further studies are required to better assess whether patients with GOLD D disease should be treated with LAMA + LABA or LAMA + LABA + ICS.

The main limitations of these analyses are that they are post hoc and not powered for statistical comparisons between subgroups. However, as the analyses were performed to confirm that the positive results of the $\mathrm{OTEMTO}^{\circ}$ study hold true for patients of all disease severities included, and for patients irrespective of prior medication use, this is not a major concern. A pattern of results for the lung-function changes noted in this subgroup analysis is that often the $95 \%$ CI for tiotropium + olodaterol versus tiotropium crossed zero for trough $\mathrm{FEV}_{1}$ but not for $\mathrm{FEV}_{1} \mathrm{AUC}_{0-3}$. This, again, is likely to be related to sample size for these subgroups and the greater effect size for $\mathrm{AUC}_{0-3}$. 
One reason why it is of interest to examine the benefits of tiotropium + olodaterol in patients by disease severity, and in patients who are treatment naive, is that the fastest decline in lung function in COPD is seen in the initial stages of the disease [20]. Thus, selecting the most appropriate treatment for initial therapy may be important. Even in mild to moderate COPD, patients start to limit exercise and activities, which are further limited as lung function declines, leading to a sedentary lifestyle [21]. It has been suggested that intervening early in COPD may benefit patients, as they are able to maintain levels of activity and health [20], and treatment may improve healthrelated quality of life and potentially slow disease progression [22]. Furthermore, a subgroup analysis of the UPLIFT $^{\circ}$ tiotropium study showed that in patients with GOLD 2 (moderate) COPD, early intervention with tiotropium appeared to slow the course of $\mathrm{FEV}_{1}$ decline [23]. Improvements in lung function are associated with better quality of life and reduced symptoms [24]. By targeting earlier disease, it is hoped that treatment may maintain the patient's functionality and postpone disease progression for longer.

\section{Conclusions}

Overall, the added benefits of tiotropium + olodaterol compared to tiotropium monotherapy in patients with moderate COPD and treatment-naive patients suggest that tiotropium + olodaterol should be considered as an option for patients at the point where there is a need to initiate maintenance therapy, as well as in patients with more severe disease.

\section{Additional file}

Additional file 1: Methodology; Table S1. Trough FEV 1 and FEV $\mathrm{AUC}_{0-3}$ responses, TDI focal score and SGRQ total score at 12 weeks in GOLD 2 and GOLD 3 subgroups (full analysis set, combined studies); Figure S1. (a) Responder analysis of SGRQ total score and (b) TDI focal score, all at 12 weeks: treatment comparisons for $T+O 5 / 5 \mu \mathrm{g}$ versus $T$ $5 \mu \mathrm{g}$ and versus placebo in patients with GOLD 2 and 3 disease, GOLD A-D disease, patients who were treatment naive/not treatment naive at baseline and for patients who were receiving/not receiving ICS treatment at baseline. (DOCX $333 \mathrm{~kb}$ )

\section{Abbreviations}

$\mathrm{AUC}_{0-3}$, area under the curve from 0 to $3 \mathrm{~h} ; \mathrm{Cl}$, confidence interval; COPD, chronic obstructive pulmonary disease; $\mathrm{FEV}_{1}$, forced expiratory volume in $1 \mathrm{~s}$; GOLD, Global initiative for chronic Obstructive Lung Disease; ICS, inhaled corticosteroids; LABA, long-acting $\beta_{2}$-agonist; LAMA, long-acting muscarinic antagonist; SGRQ, St George's Respiratory Questionnaire; TDI, Transition Dyspnoea Index

\section{Acknowledgements}

The authors received no compensation related to the development of the manuscript. Medical writing assistance was provided by Claire Scofield, MRes, and Laura George, PhD, of Complete HealthVizion.

\section{Funding}

This work was supported by Boehringer Ingelheim Pharma GmbH \& Co. KG. Medical writing assistance was contracted and compensated by Boehringer Ingelheim Pharma GmbH \& Co. KG.

\section{Authors' contributions}

All authors have contributed to the conception/design of the study, data acquisition or analysis and interpretation of the data. All authors meet criteria for authorship as recommended by the International Committee of Medical Journal Editors. They take full responsibility for the scope, direction, content of, and editorial decisions relating to, the manuscript, were involved at all stages of development and have approved the submitted manuscript. DS was the coordinating investigator of the study and participated in the design, implementation and interpretation of the study. MG, OS and GTF were study investigators and participated in the coordination and interpretation of the study. LG was the medical lead in the study and participated in the design, coordination and interpretation of the study. FV performed the statistical analyses and was involved in the interpretation of the study. All authors read and approved the final manuscript.

\section{Competing interests}

DS reports consultancy fees from Boehringer Ingelheim during the conduct of the study, grants and personal fees from Almirall, AstraZeneca, Boehringer Ingelheim, Chiesi, GlaxoSmithKline, Glenmark, Johnson and Johnson, Merck, NAPP, Novartis, Pfizer, Takeda, Teva, Therevance and Verona, and personal fees from Genentech and SkyePharma outside the submitted work. MG reports grants, consultancy fees and travel support from Boehringer Ingelheim during the conduct of the study and grants, consultancy fees and payments for lectures/Speaker Bureaus from GlaxoSmithKline, Novartis, AstraZeneca, Boehringer Ingelheim, Pfizer, ELPEN and Pharmathen outside the submitted work. OS reports grants, personal fees and non-financial support from Boehringer Ingelheim during the conduct of the study and grants, personal fees and non-financial support from Boehringer Ingelheim, Pfizer, Almirall, AstraZeneca, Chiesi, GlaxoSmithKline, Novartis, Takeda, Amgen, Cephalon, Genentech/Roche, Teva and MSD outside the submitted work. GTF reports grants, personal fees and non-financial support from Boehringer Ingelheim during the conduct of the study and grants, personal fees and non-financial support from Boehringer Ingelheim, grants and personal fees from Novartis, AstraZeneca, Pearl Therapeutics and Sunovian, grants from Forest and personal fees from GlaxoSmithKline outside the submitted work. LG and FV are employees of Boehringer Ingelheim. LB reports no conflicts of interest.

\section{Author details}

${ }^{1}$ Centre for Respiratory Medicine and Allergy, The Medicines Evaluation Unit, University Hospital of South Manchester Foundation Trust, University of Manchester, Manchester, Southmoor Road, Manchester M23 9QZ, UK.

${ }^{2}$ Athens Chest Hospital, Athens, Greece. ${ }^{3}$ Lungen- und Bronchialheilkunde, Koblenz, Germany. ${ }^{4}$ Department of Respiratory Medicine and Allergology, Lund University, Lund, Sweden. ${ }^{5}$ Boehringer Ingelheim Pharma GmbH \& Co. KG, Ingelheim, Germany. ${ }^{6}$ Pulmonary Research Institute of Southeast Michigan, Farmington Hills, MI, USA.

Received: 9 April 2016 Accepted: 3 June 2016

Published online: 18 June 2016

\section{References}

1. Global Initiative for Chronic Obstructive Lung Disease. Global strategy for the diagnosis, management, and prevention of chronic obstructive pulmonary disease. Updated 2016. http://www.goldcopd.org/. Accessed 6 Jun 2016

2. National Institute for Health and Care Excellence. Chronic obstructive pulmonary disease in over $16 \mathrm{~s}$ : diagnosis and management. Clinical guideline. NICE guidelines [CG101]. http://www.nice.org.uk/guidance/cg101/ resources/chronic-obstructive-pulmonary-disease-in-over-16s-diagnosis-andmanagement-35109323931589. Accessed 6 Jun 2015.

3. Casaburi R, Mahler DA, Jones PW, Wanner A, San Pedro G, ZuWallack RL, et al. A long-term evaluation of once-daily inhaled tiotropium in chronic obstructive pulmonary disease. Eur Respir J. 2002;19:217-24.

4. O'Donnell DE, Flüge T, Gerken F, Hamilton A, Webb K, Aguilaniu B, et al. Effects of tiotropium on lung hyperinflation, dyspnoea and exercise tolerance in COPD. Eur Respir J. 2004;23:832-40. 
5. Maltais F, Hamilton A, Marciniuk D, Hernandez P, Sciurba FC, Richter K, et al. Improvements in symptom-limited exercise performance over $8 \mathrm{~h}$ with once-daily tiotropium in patients with COPD. Chest. 2005;128:1168-78.

6. Tashkin DP, Celli B, Senn S, Burkhart D, Kesten S, Menjoge S, et al. A 4-year trial of tiotropium in chronic obstructive pulmonary disease. N Engl J Med. 2008:359:1543-54

7. Bateman ED, Tashkin D, Siafakas N, Dahl R, Towse L, Massey D, et al. A oneyear trial of tiotropium Respimat ${ }^{\oplus}$ plus usual therapy in COPD patients. Respir Med. 2010;104:1460-72.

8. Yohannes AM, Willgoss TG, Vestbo J. Tiotropium for treatment of stable COPD: a meta-analysis of clinically relevant outcomes. Respir Care. 2011;56:477-87.

9. Vogelmeier C, Hederer B, Glaab T, Schmidt H, Rutten-van Mölken MPMH, Beeh KM, et al. Tiotropium versus salmeterol for the prevention of exacerbations of COPD. N Engl J Med. 2011;364:1093-103.

10. Ferguson GT, Feldman GJ, Hofbauer P, Hamilton A, Allen L, Korducki L, et al. Efficacy and safety of olodaterol once daily delivered via Respimat ${ }^{\ominus}$ in patients with GOLD 2-4 COPD: results from two replicate 48-week studies. Int J Chron Obstruct Pulmon Dis. 2014;9:629-45.

11. Koch A, Pizzichini E, Hamilton A, Hart L, Korducki L, De Salvo MC, et al. Lung function efficacy and symptomatic benefit of olodaterol once daily delivered via Respimat ${ }^{\circledR}$ versus placebo and formoterol twice daily in patients with GOLD 2-4 COPD: results from two replicate 48-week studies. Int J Chron Obstruct Pulmon Dis. 2014;9:697-714.

12. Feldman GJ, Bernstein JA, Hamilton A, Nivens MC, Korducki L, LaForce C.

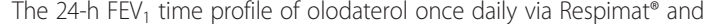
formoterol twice daily via Aerolizer in patients with GOLD 2-4 COPD results from two 6-week crossover studies. Springerplus. 2014;3:419.

13. Lange P, Aumann J-L, Hamilton A, Tetzlaff K, Ting N, Derom E. The 24 hour lung function time profile of olodaterol once daily versus placebo and tiotropium in patients with moderate to very severe chronic obstructive pulmonary disease. J Pulm Respir Med. 2014;4:196.

14. Buhl R, Maltais F, Abrahams R, Bjermer L, Derom E, Ferguson G, et al. Tiotropium and olodaterol fixed-dose combination versus monocomponents in COPD (GOLD 2-4). Eur Respir J. 2015:45:969-79.

15. Cazzola M, Rogliani P, Ora J, Matera MG. Olodaterol + tiotropium bromide for the treatment of chronic obstructive pulmonary disease. Expert Rev Clin Pharmacol. 2015;8:529-39.

16. Singh D, Ferguson GT, Bolitschek J, Grönke L, Hallmann C, Bennett N, et al. Tiotropium + olodaterol shows clinically meaningful improvements in quality of life. Respir Med. 2015;109:1312-9.

17. Beeh K-M, Westerman J, Kirsten A-M, Hébert J, Grönke L, Hamilton A, et al. The 24-h lung-function profile of once-daily tiotropium and olodaterol fixed-dose combination in chronic obstructive pulmonary disease. Pulm Pharmacol Ther. 2015;32:53-9.

18. Beeh K-M, Derom E, Echave-Sustaeta J, Grönke L, Hamilton A, Zhai D, et al. The lung function profile of once-daily tiotropium and olodaterol via Respimat ${ }^{\circledR}$ is superior to that of twice-daily salmeterol and fluticasone propionate via Accuhaler ${ }^{\oplus}$ (ENERGITO ${ }^{\oplus}$ study). Int J Chron Obstruct Pulmon Dis. 2016;11:193-205.

19. Ferguson GT, Fležar M, Korn S, Korducki L, Grönke L, Abrahams R, et al. Efficacy of tiotropium + olodaterol in patients with chronic obstructive pulmonary disease by initial disease severity and treatment intensity: a post hoc analysis. Adv Ther. 2015;32:523-36.

20. Tantucci C, Modina D. Lung function decline in COPD. Int J Chron Obstruct Pulmon Dis. 2012;7:95-9.

21. O'Donnell DE, Gebke KB. Examining the role of activity, exercise, and pharmacology in mild COPD. Postgrad Med. 2014;126:135-45.

22. Welte T, Vogelmeier C, Papi A. COPD: early diagnosis and treatment to slow disease progression. Int J Clin Pract. 2015;69:336-49.

23. Decramer M, Celli B, Kesten S, Lystig T, Mehra S, Tashkin DP, et al. Effect of tiotropium on outcomes in patients with moderate chronic obstructive pulmonary disease (UPLIFT): a prespecified subgroup analysis of a randomised controlled trial. Lancet. 2009;374:1171-8.

24. Jones PW, Donohue JF, Nedelman J, Pascoe S, Pinault G, Lassen C Correlating changes in lung function with patient outcomes in chronic obstructive pulmonary disease: a pooled analysis. Respir Res. 2011;12:161.

\section{Submit your next manuscript to BioMed Central and we will help you at every step:}

- We accept pre-submission inquiries

- Our selector tool helps you to find the most relevant journal

- We provide round the clock customer support

- Convenient online submission

- Thorough peer review

- Inclusion in PubMed and all major indexing services

- Maximum visibility for your research

Submit your manuscript at www.biomedcentral.com/submit
() BioMed Central 